\title{
$ノ-r$
}

\section{Non-Newtonian Behavior in Steady Shear Flow of Narrow Distribution Polystyrene Solutions with Low Concentration}

\author{
by \\ Yoshio ITO and Shunsuke SHISHIDO \\ (Department of Chemistry, Faculty of Science, Niigata University, Niigata 950-21)
}

\begin{abstract}
The dependence of viscosity $\eta$ on shear rate $\dot{\gamma}$ ranged from lower Newtonian to upper Newtonian flow regions has been measured for solutions of a narrow distribution polystyrene $\left(\bar{M}_{w}=3.92 \times 10^{5}, \bar{M}_{w} / \bar{M}_{n}=1.10\right)$ in diethyl phthalate at $30.0^{\circ} \mathrm{C}$. Plots of $\left(\eta-\eta_{\mathrm{fric}}\right) /$ $\left(\eta_{0}-\eta_{\text {fric }}\right)$ versus $f_{\dot{\gamma}} \tau_{R}\left(\eta_{0}-\eta_{\text {fric }}\right) / 2 \eta_{0}$ are accordant with the Graessley theoretical curve for the fluid of narrow distribution polymer, where $\eta_{0}$ is the zero shear viscosity, $\eta_{\mathrm{fric}}$ is a frictional viscosity parameter nearly independent of shear rate, and $\tau_{R}=6 \eta_{0} M / \pi^{2} c R T$. $f$ is a shift factor which is 1 for the solutions of concentrations $c$ from 0.562 to $0.0603 \mathrm{~g} / \mathrm{cm}^{3}$, and decreases with decreasing concentration below $0.0330 \mathrm{~g} / \mathrm{cm}^{3}$.

Results show that the steady shear viscosity consists of the shear dependent entanglement viscosity $\eta_{\mathrm{ent}}$ and the shear independent frictional viscosity $\eta_{\mathrm{fric}}$ and that the upper Newtonian behavior appears when $\eta_{\text {ent }}$ becomes smaller than $\eta_{\text {fric }}$ with increasing shear rate. A calculation of fractional reduction in the entanglement density under the existing shear condition shows that there remain residual entanglements even in the region of upper Newtonian flow.
\end{abstract}

\section{低濃度ポリスチレン溶液の非ニュートン流動性}

\author{
伊 藤 良夫・完戸 俊 助*
}

(原稿受理：1976年12月 1 日)

\section{1. 緒}

\section{言}

線状高分子抢よびその溶液の定常ずり粘度のずり速度依存性に 関する実験結果は, Graessley の理論と良く合うとされている ${ }^{1) ~ 6) . ~}$ しかし, 低濃度の線状高分子溶液に関する実験結果は, 溶液濃度 が低くなるほど，またずり速度が大きくなる程理論との不一致が 著しくなる ${ }^{7), 8)}$. これ飞対して, 著者らは中程度の分子量のポリ ジメチルシロキサン执よびその溶液と市販のポリスチレンのフタ ル酸ジェチル (DEP) 溶液 (15〜 50\%wt) との非ニュートン粘度

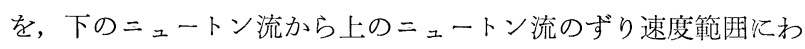
たり測定し，ずり粘度 クは Graessley のからみ合い粘度 $\eta_{\mathrm{ent}}$ と高 分子鎖間，高分子鎖と溶媒分子間，溶媒分子間等の摩擦に上る粘 度 $\eta_{\mathrm{fric}}$ とから成ると考光, これらのずり速度 $\dot{\gamma}$ 依存性は $-d \eta_{\mathrm{ent}} /$ $d \dot{\gamma} \gg-d \eta_{\mathrm{fric}} / d \dot{\gamma} \fallingdotseq 0$ と予想できることから, $\eta_{\text {fric }}$ をパラメーター として実験結果を整理した．結果は $\bar{M}_{w} / \bar{M}_{n}=2$ に詨する Graes-

\footnotetext{
* 新潟大学理学部 新潟市
}

sley 理論と良く一致している ${ }^{9) \sim 11)}$.

本研究は, 中抢よび低濃度の狭い分子量分布をもつポリスチレ ンの DEP 溶液の非ニュートン粘度を, 下のニュートン流から上 のニュートン流の範囲にわたり測定した結果を, 前報の結果と比 較しつつ Graessley の理論で整理し, 非ニュートン流動の機構に 関する知見を得ることを目的としている。

\section{2. 実験}

粘度 クは $\mathrm{N}_{2}$ ガス押出型粘度訂 ${ }^{12)}$ で測定した。 この実験では毛 細管半径 $r$ が $2.62 \times 10^{-2} \mathrm{~cm}$, 毛細管長さと半径との比 $l / r$ が 3.10 〜73.93，拈よび $r$ が $1.33 \times 10^{-2} \mathrm{~cm}, l / r$ が 5.78〜146.3の 2 種 類の毛細管の組を用いた. Bagley 末端補正は $r$ の同じ毛細管の

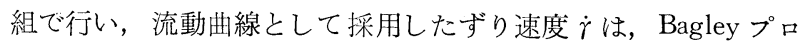
ットが直線関係を保持する範囲に限った．更に別の $r$ の毛細管の 組についての Bagley 末端補正から流動曲線を求め, 前の流動曲 線との一致を確めた。非ニュートン流補正と運動エネルギー補正 
は常法で行った。試料には Pressure Chemical 社の標準ポリスチ レン $\left(\bar{M}_{w}=3.92 \times 10^{5}, \bar{M}_{w} / \bar{M}_{n}=1.10\right)$ の DEP 溶液を用い，そ の濃度は Table 1 に記してある。

\section{3. 結果および考察}

Fig. 1 亿示した $\eta \sim \dot{\gamma}$ 関係のうち，濃度 $5.62 \times 10^{-1} \sim 6.03 \times 10^{-2}$ $\mathrm{g} / \mathrm{cm}^{3}$ の試料についての Graessley プロット $\left(\eta-V_{s} \eta_{s}\right) /\left(\eta_{0}-\right.$ $\left.V_{s} \eta_{s}\right) \sim \dot{\gamma} \tau_{R}\left(\eta_{0}-V_{s} \eta_{s}\right) / 2 \eta_{0}$ [ここで $\tau_{R}=6 \eta_{0} M / \pi^{2} c R T, V_{s}=$ 体積 分率， $\eta_{s}$ =溶媒粘度〕と， $V_{s} \eta_{s}$ のかわりに摩擦項補正として上の ニュートン粘度 $\eta_{\infty}$ を用いたとき ${ }^{13)}$ の Graessley プロットをFig. 2 に示す. Fig. 3 は Table 1 の $\eta_{\text {fric }}$ で補正した Graessley プロ ットで, 下のニュートン流から上のニュートン流までの全ずり速 度範囲にわたり，狭い分子量分布に対する Graessley の理諭曲線 と一致している. 市販のポリスチレンの DEP 溶液についての結

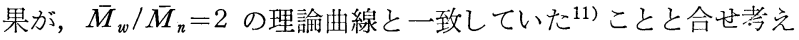
ると, 理論と実験との一致は極めて良好である。

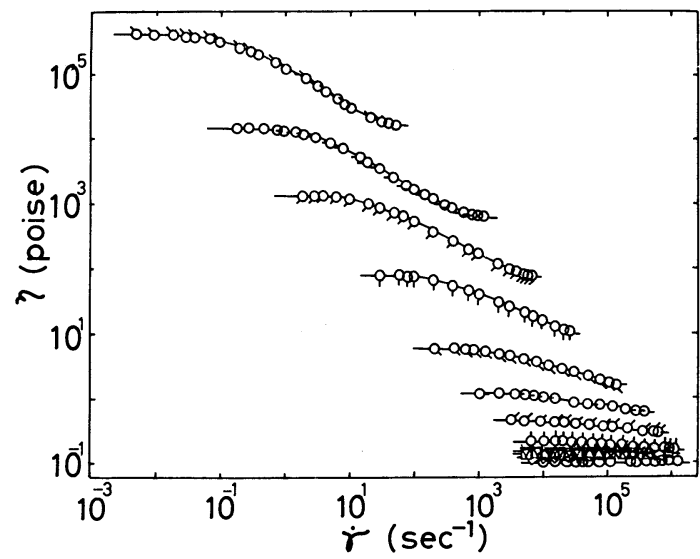

Fig. 1. Dependence of viscosity $\eta$ on rate of shear $\dot{\gamma}$ for solutions of a narrow distribution polystyrene in diethyl phthalate at various concentrations at $30.0^{\circ} \mathrm{C}$. The symbols are explained in Table 1 .
Graessley 2) によると，からみ合い密度 $E_{\dot{\gamma}}$ の $\dot{\gamma}$ 依存性は, $G(\theta)=E_{\dot{\gamma}} / E_{0}=(2 / \pi)\left\{\cot ^{-1} \theta+\theta /\left(1+\theta^{2}\right)\right\}$ 〔本研究では $\theta=\dot{\gamma} \tau_{R}(\eta$ 一 $\left.\eta_{\text {rric }}\right) / 2 \eta_{0}$ を用いた により計算できる。 $\dot{\gamma}$ によるからみ合い 密度の減少 $1-G(\theta)$ と $\left(\eta-\eta_{\mathrm{fric}}\right) /\left(\eta_{0}-\eta_{\mathrm{fric}}\right)=\eta_{\mathrm{ent}} / \eta_{\mathrm{ent}, 0}$ との 関係が Fig. 4 亿示されている. 理論（実線）と実験との一致は 極めて良い.ずり速度が上のニュートン流に到達した点での 1 $G(\theta)$ 值と $\left(\eta_{\infty}-\eta_{\mathrm{fric}}\right) / \eta_{\mathrm{fric}}=\eta_{\mathrm{ent}, \infty} / \eta_{\mathrm{fric}}$ 值とが Table 1 に記し でる.

これらの結果は, 比較的からみ合い密度が小さいと考えられる 中濃度溶液では, Graessley の提案のごとくポリマー間のからみ 合いのほどけが非ニュートン流動性の原因となり, 流れが上の二 ュートン流に到達してもな掠ポリマー間のからみ合いが残ってい ることを示す。このからみ合いを更にほどくには，極めて高い $\dot{\gamma}$ で流すことが必要であるが，この $\dot{\gamma}$ 領域では測定された粘度 ク

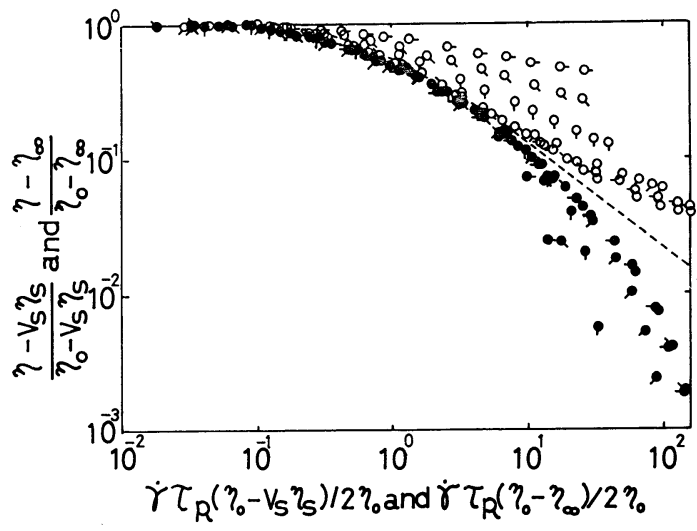

Fig. 2. Gressley's plots modified by solvent viscosity $\eta_{s}$ (open symbol) and by upper-Newtonian viscosity $\eta_{\infty}$ (closed symbol) from 0.562 to $0.0603 \mathrm{~g} / \mathrm{cm}^{3}$, where $V_{s}$ is the volume fraction of solvent and $\tau_{R}=6 \eta_{0} M / \pi^{2} c R T$. Pips are those in Table 1 . The dotted line shows the Graessley theoretical curve for $Z=10$ of ref. 2 .

Table 1. Zero-shear viscosity $\eta_{0}$, upper-Newtonian viscosity $\eta_{\infty}$, frictional viscosity $\eta_{\text {fric }}$, shift factor $f$ for reduced shear rate, ratio of upper-Newtonian entanglement viscosity to frictional viscosity $\eta_{\mathrm{ent}, \infty} / \eta_{\mathrm{fric}}$, and fractional reduction in entanglement density $1-G(\theta)_{\infty}$ at the onset of upper-Newtonian flow.

\begin{tabular}{|c|c|c|c|c|c|c|c|}
\hline $\begin{array}{l}\text { conc. } \\
\left(\mathrm{g} / \mathrm{cm}^{3}\right)\end{array}$ & symbol & $\begin{array}{c}\eta_{0} \\
\text { (poise) }\end{array}$ & $\begin{array}{c}\eta_{\infty} \\
\text { (poise) }\end{array}$ & $\begin{array}{c}\eta_{\mathrm{fric}} \\
\text { (poise) }\end{array}$ & $1 / f$ & $\eta_{\text {ent }, \infty} / \eta_{\text {fric }}$ & $1-G(\theta)_{\infty}$ \\
\hline $5.62 \times 10^{-1}$ & o & $4.07 \times 10^{5}$ & $1.56 \times 10^{4}$ & $9.2_{0} \times 10^{3}$ & & 0.696 & 0.608 \\
\hline $4.41 \times 10^{-1}$ & $-\circ$ & $1.52 \times 10^{4}$ & $6.62 \times 10^{2}$ & $4.0_{0} \times 10^{2}$ & & 0.655 & 0.648 \\
\hline $3.37 \times 10^{-1}$ & o & $1.22 \times 10^{3}$ & $7.38 \times 10$ & $5.0_{0} \times 10$ & & 0.476 & 0.521 \\
\hline $2.23 \times 10^{-1}$ & Q & $7.68 \times 10$ & 9.80 & $6.5_{0}$ & & 0.581 & 0.407 \\
\hline $1.19 \times 10^{-1}$ & a & 5.90 & 1.58 & $1.3_{0}$ & & 0.215 & 0.347 \\
\hline $6.03 \times 10^{-2}$ & o & 1.23 & $5.80 \times 10^{-1}$ & $5.3_{0} \times 10^{-1}$ & & 0.0943 & 0.353 \\
\hline $3.30 \times 10^{-2}$ & $\sigma$ & $4.58 \times 10^{-1}$ & $2.87 \times 10^{-1}$ & $2.6_{2} \times 10^{-1}$ & 1.6 & 0.0954 & 0.339 \\
\hline $1.57 \times 10^{-2}$ & o & $2.20 \times 10^{-1}$ & $1.65 \times 10^{-1}$ & $1.4_{5} \times 10^{-1}$ & 2.8 & 0.137 & 0.253 \\
\hline $1.18 \times 10^{-2}$ & $\triangle$ & $1.81 \times 10^{-1}$ & $1.45 \times 10^{-1}$ & $1.3_{0} \times 10^{-1}$ & 4.5 & 0.115 & 0.162 \\
\hline $8.13 \times 10^{-3}$ & $\nabla$ & $1.56 \times 10^{-1}$ & $1.32 \times 10^{-1}$ & $1.2_{0} \times 10^{-1}$ & 5.8 & 0.100 & 0.129 \\
\hline $5.59 \times 10^{-3}$ & $\square$ & $1.40 \times 10^{-1}$ & $1.23 \times 10^{-1}$ & $1.1_{0} \times 10^{-1}$ & 8.0 & 0.118 & 0.110 \\
\hline $3.26 \times 10^{-3}$ & $\diamond$ & $1.25 \times 10^{-1}$ & $1.15 \times 10^{-1}$ & $1.0_{3} \times 10^{-1}$ & 24.0 & 0.116 & 0.0239 \\
\hline solvent & $\bigcirc$ & $1.00 \times 10^{-1}$ & $1.00 \times 10^{-1}$ & $1.00 \times 10^{-1}$ & & & \\
\hline
\end{tabular}




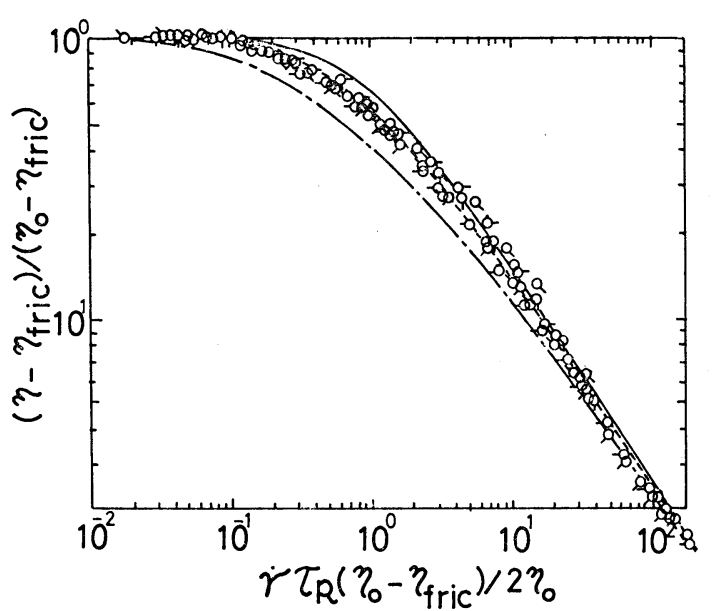

Fig. 3. Graessley's plots modified by frictional viscosity $\eta_{\text {fric }}$ in Table 1.

…. Graessley's curve for $Z=10$ of ref. 2 .

- Graessley's curve for $\bar{M}_{w} / \bar{M}_{n}=1,(Z=\infty)^{2)}$. - - Graessley's curve for $\bar{M}_{w} / \bar{M}_{n}=2,(Z=0)^{2)}$.

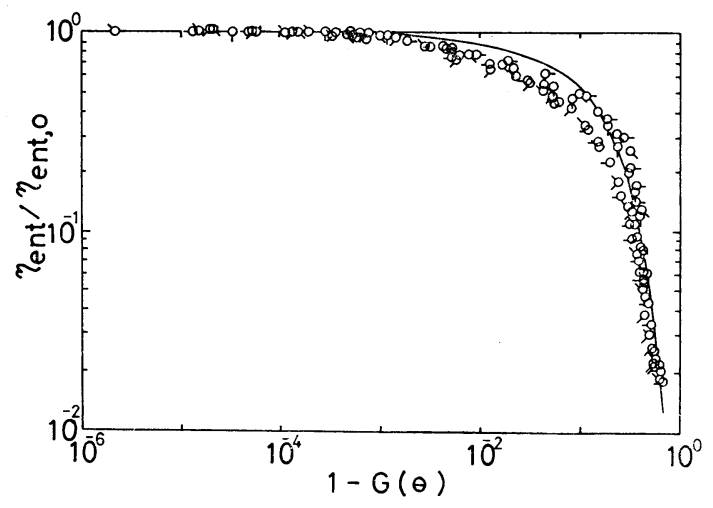

Fig. 4. Relation of relative decrease of entanglement viscosity $\eta_{\text {ent }} / \eta_{\text {ent }, 0}=\left(\eta-\eta_{\text {fric }}\right) /\left(\eta_{0}-\eta_{\text {fric }}\right)$ to fractional reduction in entanglement density $1-G(\theta)$. The solid line is a theoretical curve calculated for $Z=10$ of ref. 2 .

の大部分が $\dot{\gamma}$ 依存性のほとんどない $\eta_{\mathrm{fric}}$ 項から成るために，粘 度は事実上上のニュートン流として測定されることになる。

$3.3 \times 10^{-2} \mathrm{~g} / \mathrm{cm}^{3}$ 以下の低濃度溶液については, Table 1 の $\eta_{\text {fric }}$ の值を用いると, Graessley の理論曲線 (破線) と平行な Graessley プロット（黑印）が Fig. 6 のように得られる。これはから み合いに要する特性時間1),2) $\tau_{R}$ が中濃度の場合のように一定で なく, 濃度の減少とともに急速に減少することを暗示している。

Fig. 6 の白印は, Table 1 のシフト因子 $f$ を掛けた結果で, 中濃 度のときの狭い分子量分布 $(Z=10)$ 飞対する Graessley 曲線と 全く一致している。 $\left(\eta-\eta_{\mathrm{fric}}\right) /\left(\eta_{0}-\eta_{\mathrm{fric}}\right)$ 効 $1-G(\theta)$ のプロッ トについても, 中濃度のときの関係に完全に一致している。この 結果はからみ合いに要する特性時間 $\tau_{R}$ が異なる以外は, 低濃度 の場合と中濃度の場合とでは, 本質的に非ニュートン流動の機螣 が同じであることを示していると考えられる.

この実験に扔いて，低濃度と中濃度の分類は Graessley プロッ トに対する差異から行い, その臨界濃度は 0.0603 之 $0.0330 \mathrm{~g} / \mathrm{cm}^{3}$ の間にすった。この実験で用いた試料を $30^{\circ} \mathrm{C} て ゙$ 長持間放置する

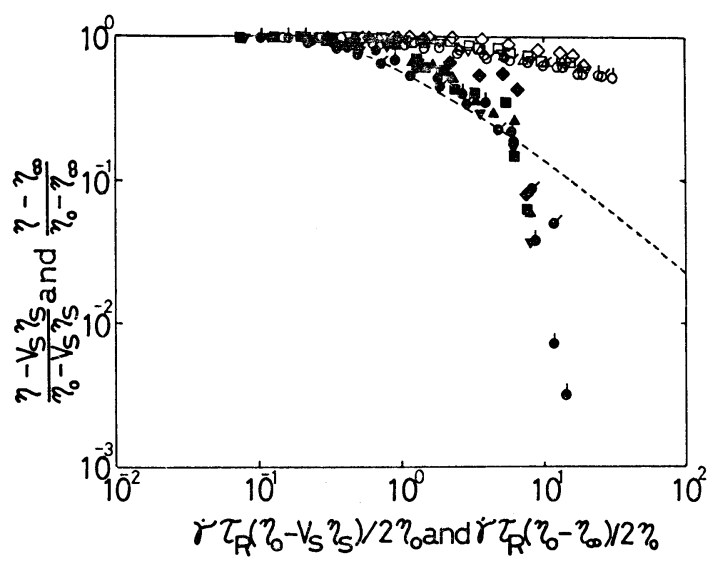

Fig. 5. Graessley's plots modified by solvent viscosity $\eta_{s}$ (open symbol) and upper-Newtonian viscosity $\eta_{\infty}$ (closed symbol) from 0.0330 to $0.00326 \mathrm{~g} / \mathrm{cm}^{3}$ (cf., Table 1), where $V_{s}$ is the volume fraction of solvent. The dotted line shows the Graessley curve $^{2)}$ for $Z=10$.

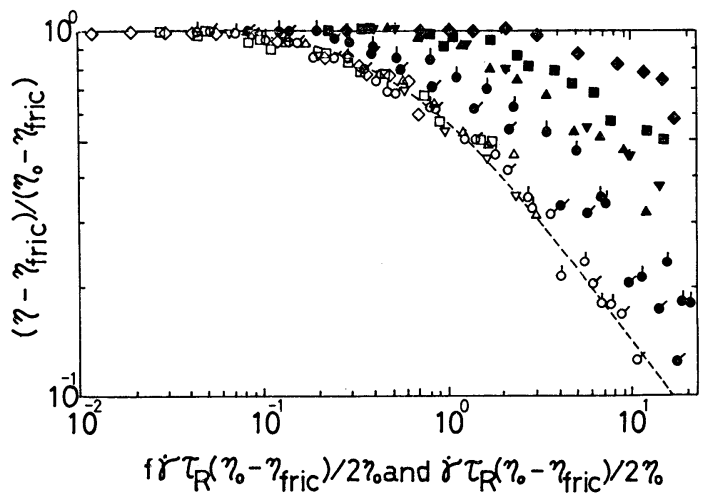

Fig. 6. Graessley's plots modified by frictional viscosity $\eta_{\text {rric }}$ in Table 1 (closed symbol) and those horizontally shifted by factor $f$ in Table 1 (open symbol). The dotted line shows the Graessley curve $^{2)}$ for $Z=10$.

と, $0.0330 \mathrm{~g} / \mathrm{cm}^{3}$ 以下の濃度の試料は透明のままであるが, $0.0603 \mathrm{~g} / \mathrm{cm}^{3}$ 以上の濃度の試料は白濁することが観察され，上の 臨界濃度と対応していて興味のある問題であるが, その他の物性 と臨界濃度との関係の詳細な検討は, 今後の課題である。

（昭和51年10月31日，第24回レオロジー討論会にて講演）

\section{文献}

1) Graessley, W.W., J. Chem. Phys., 43, 2696 (1965).

2) Graessley, W.W., J. Chem. Phys., 47, 1942 (1967).

3) Graessley, W.W., and L. Segal, Macromolecules, 2, 49 (1969).

4) Utraki, L.A., J. Polym. Sci., Polym. Phys. Ed., 12, 563 (1974).

5) Chee, K.K., Trans. Soc. Rheol., 18, 103 (1974).

6) 木内政行, 高橋雅興, 升田利实郎, 小野木重治, 日本レオ ロジー学会誌, 4, 25 (1976).

7) Bruce, C., and W.H. Schwarz, J. Polym. Sci., A-2, 7, 909 (1969). 
8) Endo, H., T. Fujimoto, and M. Nagasawa, J. Polym. Sci., A-2, 9, 345 (1971).

9) Ito, Y., and S. Shishido, J. Polym. Sci., Polym. Phys. Ed., 11, 2283 (1973).

10) Ito, Y., and S. Shishido, J. Polym. Sci., Polym. Phys. Ed., 12, 617 (1974).
11) Ito, Y., and S. Shishido, J. Polym. Sci., Polym. Phys. Ed., 13, 35 (1975).

12) Ito, Y., and S. Shishido, J. Polym. Sci., Polym. Phys. Ed., 10, 2097 (1972).

13) Graessley, W.W., Adv. Polymer Sci., 16, 132 (1974). 